\title{
Patterns of disruption of a lateralized discrimination by unilateral cortical spreading depression
}

\author{
JOAN B. LAUER \\ Indiana University-Purdue University at Indianapolis, 1201 E. 38th St., Indianapolis, Indiana 46205
}

and

\author{
GABRIEL P. FROMMER \\ Indiana University, Bloomington, Indiana 47401
}

\begin{abstract}
Rats were trained to contact drinking spouts to the left or right of their heads in response to stimulation of the left or right trigeminal nerves. The same side group $(N=9)$ contacted the spout on the same side as the stimulated nerve to get saccharin water; the opposite side group $(\mathrm{N}=8)$ contacted the spout on the side opposite to the stimulated nerve. At the start of acquisition, the same side group made more correct responses than errors of commission; the opposite side group made fewer. Unilateral cortical spreading depression increased errors of commission, errors of omission, response latency, and intertrial responding. The animals tended to respond on the spout ipsilateral to the depressed hemisphere and, for the opposite side group, on the spout on the same side as the stimulated nerve.
\end{abstract}

Although cortical spreading depression was introduced as a behavioral research tool to study memory (Bureš, 1959; Bureš, Burešová, \& Křivánek, 1974), it has been found to disrupt performance in a variety of ways. These include the following: motor deficits due to spreading depression (Moelis, 1964; Schneider \& Ebbesen, 1967), possible side effects of spreading depression on motivation (Best, 1972; Bureś, Burešová, Fifková, Olds, Olds, \& Travis, 1961; Freedman, Ferguson, \& Wilson, 1972; Levitt \& Kirkstone, 1968; Mogenson, 1965; Olds \& Travis, 1960; Rüdiger \& Fifková, 1963), nonequivalence of depressing the left and right hemispheres (Kunc, 1971), differential outcome of trials presented during low and high amplitude epochs of the cortical EEG (Freedman, Pote, Butcher, \& Suboski, 1968; Langford, Freedman, \& Whitman, 1971), and during short and long intervals between successive waves of depression (Freedman \& Bureš, 1972), sensory deficits during cortical spreading depression (Bureš. 1959; Freedman \& Langford, 1969; Pointer \& Best, 1970; Thompson \& Enter, 1967), and ipsiversive responding, the tendency to turn towards the side of the depressed hemisphere regardless of the correctness of that response (Berger \& Hogan, 1971; Ellen, 1963; Gerbrandt, Burešová, \& Bureš, 1968; Kohn, 1967; Koppman \& O’Kelly, 1966; Kukleta, 1967; Squire, 1966).

This research was supported in part by NIMH Grants 10852 and $16(1) 46$. This report is based on a dissertation submitted by the tirst author in partial fultillment of the $\mathrm{PhD}$ degree requirement at Indiana Lniversity. A preliminary report was presented at the annual meeting of the American Psychological Association, Montreal. August 1973. Address reprint requests to Joan B. Lauer. Department of Psychology. IUPUI, 1201 E. 38th Street. Indianapolis. Indiana 46205 .
The present experiment was designed to examine the contribution of sensory and sensorimotor dysfunction to the decreased level of performance which has been reported when training with no cortical spreading depression is followed by testing with unilateral cortical spreading depression (Burešová, Bureš, \& Lukaszewska, 1966; Mogenson, 1965). Spreading depression is known to abolish or attenuate primary sensory cortical evoked potentials (Bureš, 1959; Bureš et al., 1974; Freedman \& Langford, 1969). Other evidence suggests that sensory function is disrupted by this manipulation. Pointer and Best (1970) and Thompson and Enter (1967) showed that, during depression, rats exhibited increased flinch and jump thresholds. In addition, the commonly observed ipsiversive tendency during unilateral cortical spreading depression (Berger \& Hogan, 1971; Ellen, 1963; Gerbrandt et al., 1968; Kohn, 1967; Koppman \& O'Kelly, 1966; Kukleta, 1967; Squire, 1966) and the disruption of a variety of sensorimotor reactions contralateral to the depressed hemisphere may reflect, at least in part, a sensory dysfunction (Bureš et al., 1974). In the present experiment, the effect of unilateral cortical spreading depression on sensory function was tested in a lateralized two-stimulus/two-response successive discrimination task in an attempt to evaluate sensory functioning in an associative situation. Enhanced control over sensory discriminative stimuli was obtained by implanting stimulating electrodes bilaterally in the trigeminal nerves. The instrumental response, contact with one of two drinking spouts located on either side of the rat's head, was selected to minimize the influence of purely motor deficits resulting from the spreading depression. In addition, the EEG was monitored continuously to determine the level of depression throughout testing. A selective disruption of performance when the discriminative stimulus was 
contralateral to the depressed hemisphere would have been the most direct confirmation of the role of sensory dysfunction in the production of performance deficits due to unilateral cortical spreading depression. The results were considerably more complex.

\section{METHOD}

\section{Subjects}

Seventeen male albino rats derived from the Sprague-Dawley strain were successfully trained and tested. They were 90 to 120 days old and weighed an average of $350 \mathrm{~g}$ at the start of the experiment.

\section{Surgical Preparation}

The rats were anesthetized with pentobarbital $(50 \mathrm{mg} / \mathrm{kg}$, IP) and secured with the top of the skull level in a Kopf stereotaxic instrument fitted with a nontraumatic headholder (Frommer, 1971). Bipolar electrodes were constructed from Teflon-insulated stainless steel wire, 175 microns in diam, and were implanted bilaterally $2.5 \mathrm{~mm}$ caudal to and $2.5 \mathrm{~mm}$ lateral to the bregma to impale the trigeminal nerves ventral to the base of the brain. The criterion for impalement was the occurrence of a large evoked potential less than $.5 \mathrm{msec}$ after a single electric shock to the ipsilateral face and the presence of a characteristic background discharge of a population of fibers which was intensified by gently rubbing the ipsilateral face. Teflon-insulated strands of stainless steel wire were attached to stainless steel screws $(0-80,1 / 8$ in.) which were driven bilaterally into the frontal bones to serve as EEG recording electrodes, and an additional bared strand of the wire was thrust into the neck muscles to serve as ground. The leads from the electrodes were terminated in a manner described elsewhere (Frommer, 1970).

In the first nine rats, clear plastic cannulae, $3 \mathrm{~mm}$ in diam and capped with stainless steel screws, were mounted paradurally over the occipital cortex at the time of electrode implantation. When unilateral cortical spreading depression was to be elicited, $25 \% \mathrm{KCl}$ solution was injected into one of the cannulae. For the remaining eight rats, a more satisfactory method was devised. Cylinders of modeling clay, $3 \mathrm{~mm}$ in diam, were placed on the skull over the occipital cortex, and the dental cement (Caulk, Grip) used to fix the electrodes in place was formed around them. To gain access to the cortex, the night before testing under spreading depression, the modeling clay was excavated, the rats were anesthetized with ether, and a hole was drilled through the skull with a No. 51 twist drill. Following testing, the skull defect was covered with absorbable gelatin sponge, and the hole was sealed with dental cement. These two preparations were approximately equally represented in the two experimental training groups described below.

\section{Apparatus}

The discrimination training chamber was $8.5 \mathrm{~cm}$ wide and $23 \mathrm{~cm}$ long. Its $35-\mathrm{cm}$-high walls were made of clear plastic. Four pieces of aluminum tubing, $.94 \mathrm{~cm}(3 / 8 \mathrm{in}$.) in diam, ran lengthwise at the bottom. Spouts made of .62-cm- $(1 / 4 \mathrm{in}$.) diam stainless steel tubing were located on each side wall near one end of the chamber $5 \mathrm{~cm}$ above the floor. They were connected to lickometers which recorded the rat's contacts. In an attempt to isolate the animal from the programming equipment, the chamber was housed in a refrigerator shell in which 85-dB white noise was played during training and testing. Electromechanical programming equipment regulated the availability of single drops of $.4 \%$ saccharin solution at the spouts. Trigeminal nerve shocks were generated by Tektronix 160 series pulse and waveform generators which drove a transistorized constant current source through an isolating transformer. Electrical activity of the brain was led by low noise cable (Microdot No. 260-3816) to a Grass
Model 7 polygraph which also drove a Tektronix oscilloscope. A six-channel Gerbrands event recorder recorded stimulus presentations, contacts with each drinking spout, and reinforcements.

\section{Procedure}

The rats were placed on a 23.5 -h water deprivation schedule with lab chow available ad lib 9 to 12 days before the beginning of discrimination training. They were then trained by a correction procedure to obtain single drops of saccharin solution by contacting the drinking spouts on either side of the chamber, the correct one being signaled by the trigeminal nerve (left or right) which was being stimulated. The rats were randomly assigned to two groups prior to training. The same side group $(N=9)$ was required to contact the spout on the same side as the nerve being stimulated in order to obtain a drop of the saccharin water. The opposite side group $(\mathrm{N}=8)$ had to contact the spout on the side opposite to the stimulated nerve to earn reinforcement. The nerve stimulation consisted of a train of shocks delivered once per second until one of the spouts was contacted or until 10 shocks had been delivered. The intensity was adjusted individually for each animal to be just above the threshold for eliciting reflexive movement of the vibrissae. Daily discrimination training consisted of 24 trials, half having the left nerve stimulated and the other half the right, in random order. The intertrial interval ranged between 30 and $60 \mathrm{sec}$, averaging $45 \mathrm{sec}$. The day after an animal reached a criterion performance of 23 or 24 trials correct on 3 of 4 consecutive days, its discrimination performance was tested during unilateral cortical spreading depression. The procedure during testing was identical to that during training except that $\mathrm{KCl}$ was applied, and 24 to 96 trials were administered depending on the duration of the spreading depression. The criterion for the occurrence of spreading depression was the reduction of amplitude of the spontaneous EEG below $50 \%$ of the average peak-to-peak EEG amplitude (judged by inspection) prior to the application of $\mathrm{KCl}$. Some animals were retrained to criterion on the days following testing and were retested with the other hemisphere depressed. Therefore, a total of 24 observations of performance during unilateral spreading depression were obtained from the 17 animals. EEG records were collected during some control sessions prior to testing and during all test sessions, though usable records were not available throughout because of technical difficulties.

\section{Statistical Analy sis}

Because the number of trials during testing sessions under unilateral spreading depression was not constant, it was necessary to convert these data into proportions of the three kinds of responses: correct responses, errors of commission (contacts with the incorrect spout), and errors of omission (failure to respond on either spout within $10 \mathrm{sec}$ ), to be able to combine the data of the different animals. A three-factor analysis of variance was performed on these data. The proportion of correct responses and errors of commission formed one factor labeled "Correctness of Response" (errors of omission were left out of the analysis because their inclusion would make the within-subjects score for each animal add up to 1.0; however, this category could be evaluated from this analysis in that interaction in which the correctness of response factor is collapsed). The kind of trial factor consisted of the trials on which the correct spout was ipsilateral to the depressed hemisphere compared to the trials on which it was contralateral. These two factors were nested in the groups factors, in which the data from the same side group were compared with those from the opposite side group. 


\section{RESULTS}

Acquisition of the discrimination task took about 20 to 30 days. The animals learned to position themselves between the two spouts, and they rarely moved away so that they could respond promptly with a minimum of movement besides turning the head. The same side group (reinforced for contacting the spout on the same side as the nerve being stimulated) started at a higher level of performance and reached criterion sooner than did the opposite side group (reinforced for contacting the spout on the side opposite from the nerve being stimulated). However, the latter group's acquisition curve rose more steeply. These conclusions are supported by an analysis of variance on the data from the first 20 days of training, which showed significant group and days main effects $[F(1,300$ and 19,300$)=263.5$ and 11.83, $\mathrm{p}<.001]$ and Group by Days interaction $[F(19,300)=2.73, p<.001]$. The same side group made significantly more correct responses than errors of commission on each day of training ( $\chi^{2}$ tests, $p<.025$ in all cases), even the first, while the opposite side group made significantly fewer correct responses than errors of commission on each of the first 10 days of training $\left(\chi^{2}\right.$ tests, $\mathrm{p}<.05$, in all cases). Thus, the animals showed an unlearned tendency to contact the spout on the same side as the trigeminal nerve being stimulated, if they made any response at all.

Table 1 shows that, in comparison to the asymptotic performance at the end of the discrimination training, unilateral cortical spreading depression significantly increased the proportion of contacts with the incorrect spout (errors of commission, EC) and failures to respond (errors of omission, EO), the latency of the responses on the trials on which a response was made, and the number of intertrial responses (sign tests, $p<.05$ ). Both groups

Table 1

Mean Performance on Lateralized Discrimination Task During Asymptotic Control Test and During Unilateral Cortical Spreading Depression

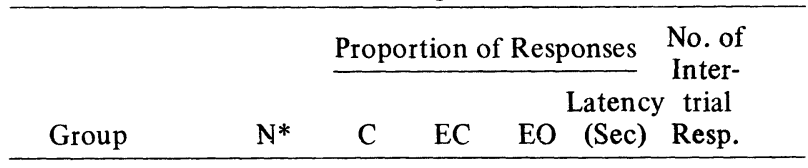

Asymptotic Control Performance

\begin{tabular}{lrrrrrr} 
Same Side & 15 & 93.6 & 5.5 & .9 & 1.4 & 16.7 \\
Opposite Side & 9 & 93.1 & 5.6 & 1.3 & 1.9 & 13.2 \\
\multicolumn{7}{c}{ Performance Under Unilateral Cortical } \\
Spreading Depression \\
Same Side & 15 & 45.2 & 20.6 & 34.3 & 3.5 & 24.2 \\
Opposite Side & 9 & 36.5 & 30.2 & 33.3 & 3.1 & 43.4
\end{tabular}

Note-C = correct responses, $E C=$ errors of commission (contacts with the incorrect spout), EO = errors of omission (failures to respond).

*Some animals were tested more than once. Therefore, the number of observations exceeds the number of animals in each group. See text.

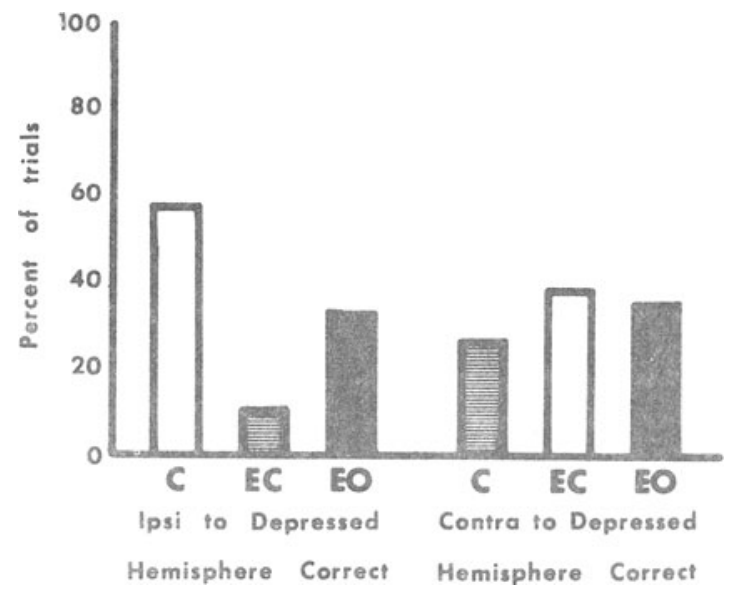

Figure 1. Percent of trials during unilateral cortical spreading depression on which the rats made correct responses (C), responses on the incorrect spout (errors of commission, EC), and no response (errors of omission, EO). The data from those trials on which responses ipsilateral to the depressed hemisphere were correct are on the left, and the data from those trials on which responses contralateral to the depressed hemisphere were correct are on the right. In this and the following figure, open bars represent responses ipsilateral to the depressed hemisphere; horizontally striped bars represent responses contralateral to the depressed hemisphere; and solid bars represent failures to respond.

of animals showed this overall disruption of performance, and there was no difference according to whether the spreading depression had been elicited on the left or on the right hemisphere ( $t$ tests, $p>.7$ ) or, with one exception, whether the depression was the first or a subsequent one in those rats which were retrained and retested after the first test $(t$ tests, $p>1)$. The exception was that rats made significantly more intertrial responses on the first test than on subsequent ones $[\mathrm{t}(8)=2.55, \mathrm{p}<.05]$.

Such an overall effect is, of course, to be expected. Of greater interest in interpreting the action of unilateral cortical spreading depression on the performance of the discrimination are the outcomes of analyses in which the data are broken down further. The bottom of Table 1 shows that, when tested under unilateral spreading depression, the same side group made about twice as many correct responses as errors of commission, while the opposite side group made about equal proportions of these two kinds of responses (Interaction: Group by Correctness of Response $[F(1,22)=4.86, p<.05])$. Figure 1 presents the same data divided according to the two kinds of trials. It shows that many more correct responses than errors of commission were made when the correct response was on the spout ipsilateral to the depressed hemisphere. When the correct response was to be directed contralateral to the depressed hemisphere, there were slightly more errors of commission than 

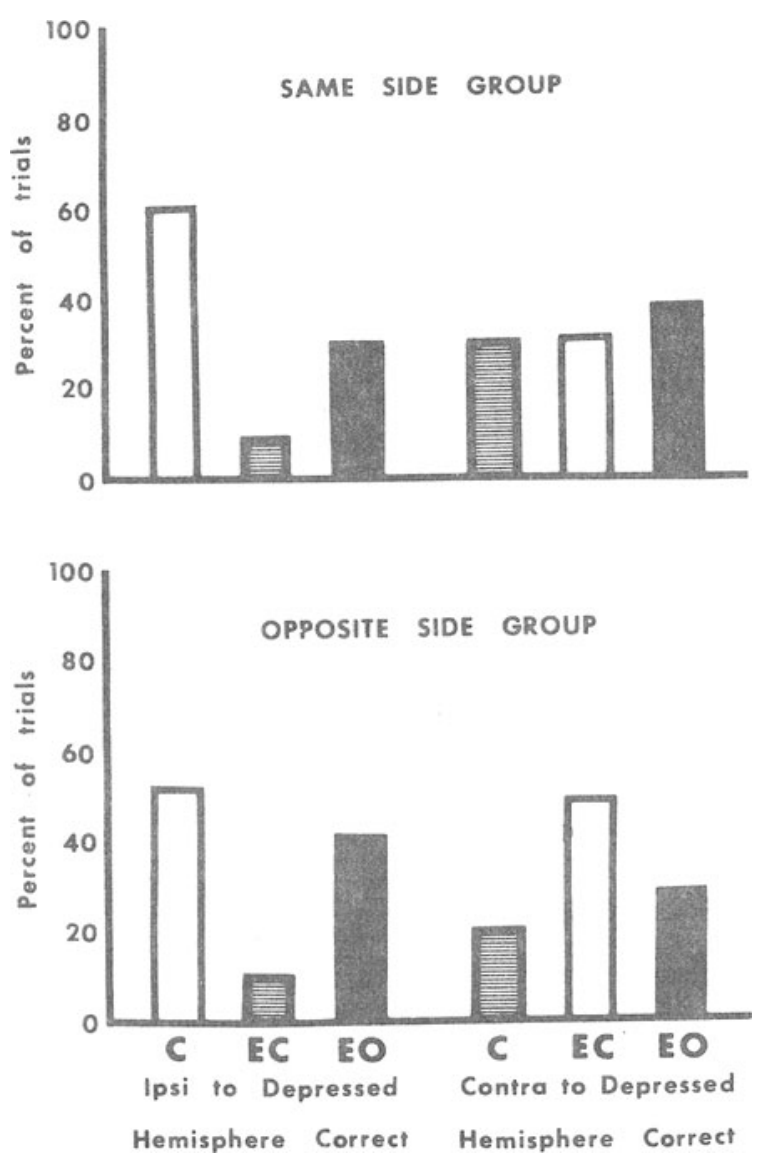

Figure 2. Percent of trials during unilateral cortical spreading depression on which the rats made correct responses (C), errors of commission (EC), and errors of omission (EO). The data are divided by groups and by kind of trial factors.

correct responses (Interaction: Kind of Trial by Correctness of Response $[F(1,22)=22.99, p<.01])$. Errors of omission were made on about one-third of the trials on both kinds of trials. Considered another way, these data show that the rats selected the spout ipsilateral to the depressed hemisphere on nearly $3 / 4$ of the trials on which they responded at all. This can be seen in Figure 1 by comparing the open bars, which represent responses on the spout ipsilateral to the depressed hemisphere, with the striped bars, which show responses on the contralateral spout. This preference was very large when it directed the animal to make a correct response, approaching control performance if the trials on which errors of omission were made are excluded. Even when responses on the spout ipsilateral to the depressed hemisphere led to errors of commission, there still remained a slight preference for that side. We refer to this phenomenon as ipsiversive responding.

Figure 2 presents the data broken down across both independent variables. Both groups of subjects were much more likely to contact the spout ipsilateral to the depressed hemisphere than the spout contralateral to it, if this was the correct response (left side of Figure 2). In contrast, if the trial required contact with the spout contralateral to the depressed hemisphere, then the proportion of correct responses declined markedly, and the magnitude of the decline depended on whether the trigeminal discriminative stimulus was ipsilateral or contralateral to the depressed hemisphere (right side of Figure 2). If the nerve stimulation was ipsilateral to the depressed hemisphere so the unlearned tendency to approach it supported the ipsiversive responding, then errors of commission to which both these processes led were much more likely to occur than were correct responses (bottom right of Figure 2). On the other hand, if the discriminative stimulus was contralateral to the depressed hemisphere so that the tendency to approach it supported the effects of the reinforcement contingency, then correct responses and errors of commission were equally likely to occur (top right hand of Figure 2). Another effect of the unilateral cortical spreading depression becomes apparent from Figure 2. Both groups showed a higher proportion of errors of omission when the discriminative stimulus was contralateral to the depressed hemisphere (upper right and lower left of Figure 2) than when it was ipsilateral (upper left and lower right of Figure 2) (Interaction: Group by Kind of Trial $[\mathrm{F}(1,22)=5.14, \mathrm{p}<.05])$. Consistent with this finding was the observation that when the stimulus was contralateral to the depressed hemisphere, the latency of the responses was longer than when it was ipsilateral $(3.8 \mathrm{sec}$ vs. $3.1 \mathrm{sec}[\mathrm{t}(23)=2.34$, $\mathrm{p}<.05]$ ).

\section{DISCUSSION}

Three processes appear to have controlled which response was made in the test under unilateral cortical spreading depression when a response did occur: (a) the tendency to turn toward and contact the spout ipsilateral to the trigeminal nerve being stimulated, which the rats apparently brought to the experimental situation; (b) the sensory discrimination established by reinforcing the rats for contacting the appropriate spout; (c) ipsiversive responding, the tendency to contact the spout ipsilateral to the depressed hemisphere. The first process can be inferred from the acquisition curves of the two groups of subjects. The opposite side group (which was required to contact the spout on the side opposite the stimulated nerve) made significantly fewer correct responses than errors of commission on each of the first 10 days of training. In contrast, the same side group (which was reinforced for contacting the spout on the same side as the stimulated nerve) made significantly more correct responses than errors of commission even on the 1st day of training. The second process, the discrimination training, was under experimental control, and its efficacy in controlling behavior was established by the strict criterion to which the rats were trained. The third process, the ipsiversive tendency, is indicated by the high proportion of contacts with the spout ipsilateral to the depressed hemisphere, regardless of whether they were correct or not. 
Of the three processes, the ipsiversive tendency seems to have been the most powerful in controlling performance in the test sitatuation. The tendency to turn toward the nerve stimulation and the sensory discrimination training were considerably weaker. This inference can be made from Figure 2. The left-hand portion of that figure shows that when the ipsiversive tendency and reinforcement contingency associated with the discriminative stimulus both tended to initiate the same response, that response was very likely to occur if any response was made at all. The tendency to contact the spout on the side on which the nerve stimulation was delivered made little difference, reducing the proportion of errors of omission slightly if it was also synergistic with the other two processes. On the other hand, when the ipsiversive tendency and the reinforcement contingency associated with the discriminative stimulus were antagonistic, calling out opposite responses, the outcome depended heavily on whether the response-directing tendency of the nerve stimulation was antagonistic to or synergistic with the ipsiversive tendency. If it competed with the ipsiversive tendency and supported the learned response to the discriminative stimulus, then the proportion of responses following the ipsiversive tendency (errors of commission) was about equal to the proportion of responses following the other two processes (correct responses). If, instead, the unlearned response to the discriminative stimulus tended to elicit the same response as the ipsiversive tendency (that is, if the discriminative stimulus was ipsilateral to the depressed hemisphere), then these processes together largely overrode the effects of the reinforcement history to produce a high proportion of errors of commission. Thus, the ipsiversive tendency was about equal to the other two processes combined in controlling the behavior in the testing situation. When combined with either one of them, it largely overrode the effect of the remaining one. Learned sensory control of behavior in the present test situation during unilateral cortical spreading depression is relatively weak.

The present data, therefore, reflect a process or processes that are more complex than a simple failure to respond to discriminative stimuli contralateral to the depressed hemisphere. Such an outcome would have been the simplest one supporting the sensory dysfunction hypothesis that the present experiment was designed to test. Nevertheless, the data do appear to be consistent with this hypothesis. Indirect support for it can be derived from the ipsiversive tendency which may reflect, at least in part, the effects of sensory dysfunction on the side contralateral to the depressed hemisphere (Bureš et al., 1974). This tendency cannot readily be accounted for by a purely motor deficit, because it occurred the least when both the discriminative stimulus and the correct response were contralateral to the depressed hemisphere, indicating that the rats did have the motor capacity to make contralateral responses if enough processes evoked them, nor can it be readily explained by sensorimotor integrative deficits because of two findings. First, the animals responded correctly on only $60 \%$ of the trials when both discriminative stimulus and the correct response were ipsilateral to the depressed hemisphere; and, second, they did respond correctly on $83 \%$ of the trials on which they responded at all when the stimulus was contralateral and the response ipsilateral to the depressed hemisphere. Other kinds of unilateral cerebral insult often produce contralateral performance deficits which are interpreted as resulting from sensory neglect (e.g., Marshall \& Teitelbaum, 1974; Orem, Schlag-Rey, \& Schlag, 1973; Schlag-Rey \& Lindsley, 1970; Watson, Heilman, Miller, \& King, 1974). Conversely, electrical stimulation can facilitate sensory reactivity contralateral to the site of stimulation (Flynn, 1973; Smith, 1972).

Other evidence in support of the role of sensory dysfunction in the present experiment can be found in the errors of omission which have yet to be considered. The more direct evidence comes from the finding that these errors were more likely to occur when the discriminative stimulus was contralateral to the depressed hemisphere than when it was ipsilateral. Less direct support may be found in a consideration of why the animals made such errors on roughly one-third of all the trials. The explanation which best appears to fit all aspects of this observation is Schneider's (1967) stimulus control hypothesis. This hypothesis states that when animals are tested with a condition of cortical depression differing from that which existed during training, the observed deficit in performance is due to a failure of generalization from the training to the testing situation. The present data do not appear to be inconsistent with this explanation, and the subsequent results of Lauer and Lauer (Note 1) appear to support it. They showed that, after rats had received preliminary experience approaching and drinking from a spout located straight ahead, unilateral cortical spreading depression produced an ipsiversive tendency but no errors of omission on a free choice between two lateralized spouts. Apparently, prior training to respond to a discriminative stimulus may be necessary to produce errors of omission in this task. Lauer and Lauer's (Note 1) data also seem to rule out motivational or motor deficits as the primary cause of the errors of omission. An explanation in terms of disruption of sensorimotor integration or motor function also seems inadequate, because the rats failed to respond on $30^{\circ} \%$ or more of the trials, even when the discriminative stimulus and the correct response were both ipsilateral to the depressed hemisphere. Burešová et al. (1966) have proposed an explanation in terms of memory deficit for the results of experiments using designs similar to that of the present study. They suggested that memory traces in more complex tasks (the only ones which showed deficits when trained with both hemispheres normal and tested with one 
hemisphere depressed) either may involve the hemispheres linked in succession rather than in parallel, or, more probably, may be disrupted by the external inhibition elicited by the disturbing new situation resulting from functional decortication of one hemisphere. There appears to be no independent evidence to support the first alternative; and the second, which Burešová et al. (1966) appear to favor, is less a memory hypothesis than a version of Schneider's (1967) stimulus control hypothesis. Finally, the physiological state of the cerebral hemispheres during unilateral cortical spreading depression may produce errors of omission. Freedman and his co-workers (Freedman et al., 1968; Freedman \& Bureš, 1972; Langford et al., 1971) have shown that performance variations during bilateral cortical spreading depression could be correlated with variations in the amplitude of the EEG and in the interval between successive waves of depression. However, examination of the EEG records obtained in the present experiment failed to reveal any simple consistent relation between the state of the EEG and the occurrence of either kind of error, possibly because only unilateral depression was elicited. Freedman and Langford (1969) have also shown that unilateral cortical spreading depression attenuates visual evoked responses not only in the depressed hemisphere but also on the untreated one, though not as much. The untreated hemisphere cannot therefore be considered to function normally.

\section{REFERENCE NOTE}

1. Lauer, J. B., \& Lauer, D. W. Sensory attention and laterality of responding during cortical spreading depression. Paper presented at the annual meeting of the Midwestern Psychological Association, Chicago, May 1975.

\section{REFERENCES}

Berger, B., \& Hogan, T. P. Right-left response differentiation in rats with unilateral cortical spreading depression. Psychonomic Science, 1971, 25, 307-308.

BEST, P. J. Effects of shock intensity on transfer of shock avoidance under unilateral spreading depression. Physiology and Behavior, 1972, 8, 279-282.

BuREš, J. Reversible decortication and behavior. In M. A. Brazier (Ed.), Conference on the central nervous system and behavior. New York: Josiah Macy, Jr. Foundation, 1959. Pp. 207-248.

Bureš, J., Burešová, O., Fifková, E., Olds, J., Olds, M. J., $\&$ Travis, R. P. Spreading depression and subcortical drive centers. Physiologia Bohemoslovenica, 1961, 10, 321-331.

Bureš, J., Burešová, O., \& KřrváneK, J. The mechanism and applications of Leão's spreading depression of electroencephalographic activity. New York: Academic, 1974.

Burešová, O., Bureš, J., \& Lukaszewska, I. Strain differences in retrieval of unilateral and bilateral engrams. Physiology and Behavior, 1966, 1, 331-333.

ELLEN, P. Spreading depression and position responses during conflict. American Psychologist, 1963, 18, 431. (Abstract)
FLynN, J. P. Patterning mechanisms, patterned reflexes, and attack behavior in cats. In J. K. Cole \& D. D. Jensen (Eds.), Nebraska Symposium on Motivation, 1972. Lincoln, Neb: University of Nebraska Press, 1973. Pp. 125-153.

Freedman, N. L., \& Bureš, J. Conditions of phasic impairment of avoidance responding during bilateral spreading depression. Journal of Comparative and Physiological Psychology, 1972, 78, 433-441.

Freedman, N. L., Ferguson, D. G., \& Wilson, D. Regulatory and nonregulatory effects of functional decortication on eating in rats. Journal of Comparative and Physiological Psychology, 1972, 81, 233-242.

Freedman, N. L., \& LANGFord, A. Visual evokedresponse attenuation by spreading depression. Journal of Comparative and Physiological Psychology, 1969, 69, 362-367.

Freedman; N. L., Pote, R., Butcher, R., \& Suboski, M. D. Learning and motor activity under spreading depression depending on EEG amplitude. Physiology and Behavior, 1968, 3, 373-376.

Frommer, G. P. A simple method for terminating chronically implanted electrodes in small animals. Physiology and Behavior, 1970, 5, 1501-1502.

FromMER, G. P. Modified nontraumatic headholder. Behavioral Research Methods \& Instrumentation, 1971, 3, 225-226.

Gerbrandt, L. K., Burešová, O., \& Bureš, J. Discrimination and reversal learning followed by a single ECS. Physiology and Behavior, 1968, 3, 149-153.

KонN, B. Spreading depression and stimulus control of interhemispheric transfer. Neuropsychologia, 1967, 5, 275-280.

Koppman, J. W., \& O'KeLLY, L. I. Unilateral cortical spreading depression: A determiner of behavior at a choice point. Journal of Comparative and Physiological Psychology, 1966, 62, 237-242.

KukLETA, M. The use of unilateral cortical spreading depression in the study of subcortical storage of memory traces in rats. Physiology and Behavior, 1967, 2, 301-304.

Kunc, L. Asymmetry of hemispheres studied by means of unilateral cortical spreading depression in rats. Activitas Nervosa Superior, 1971, 13, 13-17.

Langford, A., Freedman, N. L., \& Whitman, D. Further determinants of interhemispheric transfer under spreading depression. Physiology and Behavior, 1971, 7, 65-71.

Levitt, R. A., \& Kirkstone, B. J. Cortical spreading depression and thirst. Physiology and Behavior, 1968, 3, 421-423.

Marshall, J. F., \& Teitelbaum, P. Further analysis of sensory inattention following lateral hypothalamic damage in rats. Jouranl of Comparative and Physiological Psychology, 1974, 86, 375-395.

MoElis, I. An evaluation of the effects of spreading cortical depression on motor aspects of performance. (Doctoral dissertation, University of Illinois, 1963). Dissertation Abstracts, 1964, 24, 5547. (University Microfilms No. 64-6115)

Mogenson, G. L. Effect of spreading cortical depression on avoidance responses conditioned to peripheral or central stimulation. Electroencephalography and Clinical Neurophysiology, 1965, 18, 663-669.

Olds, J., \& Travis, R. P. Spreading depression and self-stimulation. Federation Proceedings, 1960, 19, 293. (Abstract)

Orem, J., Schlag-ReY, M., \& Schlag, J. Unilateral visual neglect and thalamic intralaminar lesions in the cat. Experimental Neurology, 1973, 40, 784-797.

Pointer, J. E., \& Best, P. J. Effects of KC1 induced cortical spreading depression on shock sensitivity. Proceedings of the 78th Annual Convention of the American Psychological Association, 1970, 5, 189-190.

Rüdiger, W., \& Fifková, E. Operant behavior and subcortical drive during spreading depression. Journal of Comparative and Physiological Psychology, 1963, 56, 375-379. 
Schlag-Rey, M., \& Lindsley, D. B. Effects of preirontal lesions on trained anticipatory visual attending in cats. Physiology and Behavior, 1970, 5, 1033-1041.

SChNeIDER, A. M. Control of memory by spreading cortical depression: A case for stimulus control. Psychological Review, 1967, 74, 201-215.

Schneider, A. M., \& Ebresen, E. Interhemispheric transfer of lever pressing as stimulus generalization of the effects of spreading depression. Journal of the Experimental Analysis of Behavior, 1967, 10, 193-197.

SмIтн, D. A. Increased perioral responsiveness: A possible explanation for the switching of behavior observed during lateral hypothalamic stimulation. Physiology and Behavior, 1972, 8, 617-621.

SQUIRE, L. R. Transfer of habituation using spreading depression. Psychonomic Science, 1966, 5, 261-262.
Squire, L. R., \& Liss, P. H. Control of memory by spreading cortical depression: A critique of stimulus control. Psychological Review, 1968, 75, 347-352.

Thompson, R. W., \& Enter, R. Shock level and unconditioned responding in rats under sham, unilateral or bilateral spreading depression. Journal of Comparative and Physiological Psychology, 1967,63, 521-523.

Watson, R. T., Heilman, K. M., Miller, B. D., \& King, F. A. Neglect after mesencephalic reticular formation lesions. Neurology, 1974, 24, 294-298.

(Received for publication April 16, 1975; accepted April 29, 1975.) 